\title{
RESENHA: Viagem solitária: memórias de um transexual trinta anos depois
}

\author{
Karine Jacques Hentges \\ Universidade Federal de Pelotas - Brasil \\ karinejhentges@gmail.com
}

Resenha: NERY, João Walter. Viagem solitária: memórias de um transexual trinta anos depois. $1^{\text {a }}$ Ed. São Paulo: Leya, 2011.

Viagem Solitária: memórias de um transexual 30 anos depois uma autobiografia escrita por João W. Nery um transexual FtM (Female to Male), em que ele descreve os percalços enfrentados para conseguir 'adequar' seu corpo feminino à sua identidade masculina.

O livro apresenta uma introdução em que Millos Kaiser. Conta sua surpresa ao conhecer João Nery e sua dificuldade em compreender um homem que nasce no corpo de uma mulher. $\mathrm{O}$ autor ainda exibe $\mathrm{o}$ prefácio, escrito por Antonio Houaiss, de seu primeiro livro denominado Erro de Pessoa o qual conta o período de sua infância até as primeiras cirurgias por ele realizadas. Viagem Solitária é escrito quase 30 anos após a primeira edição de Erro de Pessoa, e inclui agora sua vida após o relatado neste último.

O presente livro é dividido em quatro partes, quais sejam: parte I - Desencontros; parte II - Descobertas; parte III Metamorfose e por fim; parte IV Paternidade. Cada uma dessas partes de dividem em diversos capítulos.

$\mathrm{Na}$ primeira parte do livro denominada Desencontros, João conta os acontecimentos de sua vida desde a infância até a fase adulta. $\mathrm{O}$ autor relata o que gostava quando criança, suas brincadeiras, a preferência brinquedos sócio e culturalmente atribuídos a meninos. João Nery afirma não se encontrava naquele corpo ao qual pertencia, "era como se quisesse dizer a todas as pessoas que o meu físico não era aquele, ou melhor, fazê-las entender que meu corpo mentia contra mim" (p.33). Descreve as formas com que era tratado pelos outros meninos na rua e/ou na escola e como enfrentou essa contradição entre sua autoimagem e a imagem que as pessoas faziam dele.

O primeiro beijo de João aconteceu em uma brincadeira com sua prima Suzana. Durante sua adolescência nenhuma paixão foi correspondida. Seu primeiro amor correspondido foi Lúcia, era amiga de sua prima Suzana, mas depois de alguns beijos desapareceu.

$\mathrm{O}$ autor relata toda a sua angústia no que se refere ao seu corpo. Um dos artifícios utilizados para a inibição das características femininas que vinham despontando no seu corpo na adolescência foi a prática de esportes, em especial o salto ornamental. Os esportes fizeram com que seu corpo ficasse musculoso o que aumentou sua autoestima.

Ainda na adolescência, processo de socialização, João passou por duas fases, a primeira em que tentou ser mulher e aceitar os aspectos femininos em sua identidade, e a segunda quando se dá conta de que ser mulher não era possível e que decide enfrentar as agruras de se assumir como algo que nem ele sabia nomear, um homem ainda em corpo de mulher.

Aos 19 anos João entra na faculdade de Psicologia e começa a estudar teorias acerca da sexualidade, relata no livro que "por meio das pesquisas de antropólogos culturalistas americanos, descobri que a conduta sexual humana é padronizada de acordo com a própria cultura e, por essa razão, pode apresentar múltiplas variações" (p.71).

João conheceu muitas mulheres, a primeira delas foi Dolores, apesar de não ser adepto aos papéis bem definidos em uma relação, para que não houvesse confusão isso passou a ser importante em sua relação com 
ela . "Por falta de definição apriorística, dando margem a me confundir com uma mulher, a clareza de papéis passou a ser um recurso indispensável, para maior integração comigo e com a parceira" (p.77).

Mercedes foi sua segunda mulher, ficaram juntos seis anos. Esse foi um momento muito importante para João, passou a sustentar-se e a manter a casa, foi também nesse período que assumiu sua identidade masculina.

As primeiras cirurgias também acontecem nesse momento. Os seios eram uma das características femininas que mais o incomodavam, quando se olhava no espelho e os via sentia que todas as intenções de se tornar homem tinham falhado. Foram duas cirurgias nos seios, na primeira, João pediu que o médico deixasse os seios o menor possível, como não se cuidou no pósoperatório, teve que fazer outra cirurgia para corrigir as imperfeições.

Após parar de trabalhar como taxista, João foi indicado por uma grande amiga Isabela, a dar aulas no curso de Psicologia em uma faculdade. Inicialmente quando se apresentava para as turmas sentia que sua imagem causava choque e ao mesmo tempo curiosidade, mas logo conseguia conquistar os estudantes. Acabou se envolvendo com algumas alunas, mesmo sendo casado com Mercedes, optou então por se separar. Sobre a relação com as alunas ele relata,

Parece incrível e mesmo um desperdício, mas só consegui usufruir um prazer verdadeiro depois que o "coito perceptivo" estivesse consumado. Era quando me certificava de que a parceira me percebia como um homem e estava atraída mais pelo que sentia do que propriamente pelo que via no meu corpo (p.127).

\section{Parte II - Descobertas}

Em 1975 João viajou para a Europa. Em uma livraria em Paris encontrou uma revista científica que falava sobre cirurgias transgenitais realizadas em transexuais femininas. Desde então as cirurgias viraram a meta de sua vida.

Amanda foi um dos grandes amores de João. Era sua aluna e apesar de ter sido avisado que não se envolvesse com alunas, ele não resistiu. Aos 26 anos João ainda vivia na constante angustia de representar dois papéis antagônicos. Encontrou-se então com uma amiga psicóloga que havia se especializado em Sexologia na Bélgica. Lilian o indicou um médico endocrinologista, Dr. Porto, que vinha desenvolvendo um trabalho com transexuais. João entrou em contato e conseguiu uma consulta com o médico. Nessa consulta Dr. porto explicoulhe todo o processo a que seria submetido, e se constatado que ele era um caso de ele seria encaminhado às cirurgias. Porém falou-lhe também que os casos de transhomem (FtM) eram raros e as cirurgias mais complexas.

Para o início desse processo foram exigidos alguns exames hormonais que deram todos normais. Começou a psicoterapia e após conversaria com a assistente social. Com o início dessa fase revelou para seus familiares o que estava acontecendo.

Dr. Porto, em uma das consultas, convidou-o para ir para São Paulo conversar com um cirurgião plástico que já havia realizado algumas cirurgias em transexuais femininos. Farina era um cirurgião plástico conceituado. Explicou a João que já havia feito cirurgias em transmulher ( $\mathrm{MtF}$ - Male to Female) e que em todas, os resultados tinham sido satisfatórios. Farina afirma que se fosse comprovado que João era trans ele realizaria a cirurgia, nessa época essas cirurgias eram ilegais no país.

Chegou o prazo em que o psiquiatra daria definitivamente o laudo com seu parecer favorável ou não as cirurgias. Ao ser questionado, o médico disse que não podia 
lhe dar o laudo de transexual, pois não sabia se realmente acreditava que a transexualidade existia. Aquele laudo era a única maneira dele poder realizar as cirurgias. João conheceu outro psiquiatra indicado por Farina, Dr. Lourenço então falou que daria o laudo se estivesse realmente convencido de que João era um caso de transexualidade, para isso exigia uma entrevista com João e sua mãe. A mãe de João acabou aceitando ir ao consultório do médico. Antes de sua mãe voltar para a cidade onde morava, João decide procurá-la para uma conversa. João percebe seu sofrimento e desabafa, explica que em diversos momentos tentou ser mulher mesmo não se reconhecendo como tal. Dias depois Mariana conta que sua mãe mandou uma carta ao Dr. Lourenço dizendo que apoiava a cirurgia.

\section{Parte III - Metamorfose}

O laudo de Dr. Lourenço foi favorável, portanto poderiam iniciar as cirurgias. Farina explicou-lhe que a primeira cirurgia seria para preparar o campo para as próximas. Nessa cirurgia foi feita a ablação dos seios e a criação de uma neouretra. Ao retirar os pontos João ficou exultante por não ter mais seios e poder urinar em pé. João cuidou-se muito no pós-operatório, mesmo assim surgiram algumas fístulas na sua uretra. Ao voltar a São Paulo iniciou a hormonoterapia.

Quando João recebeu a visita da mãe de Amanda, percebeu que precisava utilizar usar alguma coisa que desse a impressão de ter um pênis. Começou a usar meias na região genital de modo a imitar o volume de um pênis. Passou a usar diariamente mesmo depois de sua sogra ir embora. Se sentindo impotente por não ter um pênis real ele começa a evitar as relações sexuais com Amanda.

Recuperado da primeira cirurgia João decide que está na hora de fazer a segunda operação chamada pan-histerectomia, na qual seriam retirados todos os órgãos genitais internos. Nessa etapa cirúrgica João foi ajudado por uma velha amiga da família, Dra Elizabeth obstetra-ginecologista que o indicou para o Dr. Gabriel, o qual aceitou fazer a cirurgia.

Recuperado dessa cirurgia João aguardava ansioso as próximas etapas. Recebeu então uma carta de Van, sua irmã, em que dizia que na Europa os procedimentos eram basicamente os mesmos do Brasil, e que a maioria dos trans de lá paravam as cirurgias exatamente na etapa em que João estava.

João conhece Selma uma transmulher operada. Ela manifestou interesse em saber sobre a situação legal de João. Ele então contou que continuava com os documentos originais de mulher e que isso o preocupava diante da sua imagem cada vez mais masculina. Selma o ajudou a tirar uma certidão de nascimento com $o$ nome masculino. Ele foi registrado como João Walter Nery, 18 anos.

Certo dia João abre o jornal e lê que Farina havia sido condenado por ter operado Waldir Nogueira para se tornar mulher. João ficou perplexo, sem saber o que fazer. Quem o ajudou foi Fernando, ex-marido de Leila. Fernando havia documentado alguns casos de cirurgias reconstrutoras de pênis, quando o paciente tinha sofrido algum acidente. Portanto ele sabia que o pênis ficaria praticamente insensível e que seriam necessárias muitas cirurgias. João lembrou-se do que Van havia dito sobre os trans na Europa, acabou desistindo de prosseguir com as cirurgias. Aqui no Brasil essas cirurgias, chamadas de resignação sexual só seriam permitidas 20 anos depois e continuavam sendo experimentais.

\section{Parte IV - Paternidade}

João conheceu Lola, começaram um relacionamento que durou 8 anos. Foi Lola que o incentivou a lançar seu primeiro livro - 
Erro de Pessoa, usando um pseudônimo. Um dia, ao chegar em casa do trabalho Lola reclamou de enjoo e admitiu a possibilidade de estar grávida de outro homem. Mesmo atordoado com a notícia, João percebeu como a vontade de ser pai era grande e decidiu que seria o pai dessa criança, desde que ele não tivesse que dividir a paternidade com ninguém.

Aos quatro meses descobriram que era um menino e João sugeriu o nome de Yuri. Estorou a bolsa de Lola e foram para o hospital. João assistiu o parto e foi o $2^{\circ}$ a segurar Yuri no colo, conferiu se ele era perfeitinho.

Após um período Lola teve que voltar ao trabalho e como João fazia bicos sem horário fixo, foi ele que se encarregou dos principais cuidados com o filho. Aos 4 anos Yuri encontrou a prótese de João e o questionou como ele conseguia tirar o pênis, perguntou também sobre as cicatrizes, ao que João inventou um acidente. Mas o que João temia acabou acontecendo e Lola decidiu separar-se dele.

Através de uma amiga João conheceu Sandra. Ao lerem poemas na casa de João, Sandra tira de sua bolsa e entrega a ele uma cópia de Mosca Azul de Machado de Assis. João a chama para dançar e se beijam, estão juntos há 15 anos. Foi assim que nasceu outra poesia - A lagartixa azul.

Aos 13 anos João decidiu que era a hora de contar. Iniciou explicando o quanto o amava e que tinha uma historia diferente dos outros pais, até contar-lhe que não era seu pai biológico.

Depois de um tempo Lola contou toda a historia de João ao filho. Yuri fugiu desesperado para a casa de João. Aos poucos os ânimos foram se acalmando e a relação entre eles melhorou. João explicou ao filho sua identidade ilegal e pediu discrição. João também falou de seu livro e mais tarde colocou um exemplar na sua estante.
As coisas estavam melhorando, porém o peso da idade se apresentava. João envelheceu e o pênis não veio. João começou a se dar conta de que seus amigos também envelheciam e alguns começavam a falecer. Com a ajuda de Davi, João entrou em contato com Amadeus e Darcy e combinaram de se ver no feriado de páscoa. Todos eram trans, mas somente Darcy havia feito a neofaloplastia e por isso tinha muitas cicatrizes no abdômen, de onde foram tirados os enxertos para a construção do pênis. Nesse encontro conversaram suas vidas e tudo o que já haviam passado para se assumirem enquanto homem. Davi comentou sobre a metoidioplastia uma nova técnica cirúrgica para fazer o pênis a partir do clitóris já aumentado pelos hormônios

Ela consiste basicamente em soltar os ligamentos internos do clitóris, para que ele ganhe um pouco mais de tamanho. O máximo que se conseguiu até hoje, foi que chegasse a dez centímetros. As etapas seguintes são a colpectomia, que é a retirada da mucosa vaginal e seu fechamento, e a escrotoplastia, para a criação da bolsa escrotal. Os testículos são feitos com implantes de solução salina de gel sólido (p. 307).

João questionou-lhes sobre o que pensavam do homem grávido, ao que disseram achar muito estranha a situação, tendo em vista que a maternidade é tão intimamente associada à feminilidade. João disse ter ficado feliz por os trans estarem assumindo seus desejos e ousando na desconstrução do gênero, mas mesmo assim achava a adoção uma estratégia melhor. João se deu conta que apesar de serem todos trans, eram muito diferentes.

Recebido em 20 de março de 2014. Aceito em 25 de junho 2014. 